\title{
FRECUENCIA DE Neospora caninum EN PERROS DE ESTABLOS LECHEROS DEL VALLE DE LIMA
}

\author{
Jorge del Campo S. ${ }^{1}$, Amanda Chávez V. ${ }^{2}$, Alfredo Delgado C. ${ }^{3}$, Néstor Falcón P. ${ }^{4}$, \\ Ângela Ornelas A. ${ }^{5}$, Eva Casas A. ${ }^{2}$ y Enrique Serrano M. ${ }^{2}$
}

\section{Abstract}

Neosporosis is a parasitic disease caused by Neospora caninum that produces nervous signs in dogs, the definite host, and may affect reproduction in dairy cattle. The objective of the study was to determine the frequency of $N$. caninum in dogs of dairy farms in the Lima valley. Samples from a total of $104 \mathrm{dogs}$ older than 3 months of age from 23 dairy farms, were collected and analyzed by the indirect immunofluorescense test to detect antibodies against $N$. caninum. The results indicated that $32.7 \pm 9.0 \%(34 / 104)$ were positive to $N$. caninum in a dilution of 1:50. The Huaura and Huaral provinces had the highest proportion of seropositives $(58.8 \%, 10 / 17)$. No significant differences were found due to sex and age.

Key words: Neospora caninum, dogs, neosporosis, IFA, abortion

\section{Resumen}

La neosporosis es una enfermedad parasitaria ocasionada por el Neospora caninum, que cursa con problemas reproductivos en el ganado lechero y signos nerviosos en el perro, el cual es el hospedero definitivo. El objetivo del estudio fue determinar la frecuencia de $N$. caninum en perros de establos lecheros del valle de Lima. Se evaluaron 104 muestras de suero de caninos mayores a 3 meses de edad, provenientes de 23 establos lecheros, mediante la detección de anticuerpos contra $N$. caninum a través de la prueba de inmunofluorescencia indirecta. El $32.7 \pm 9.0 \%$ (34/104) de las muestras fueron positivas a $N$. caninum en una dilución de 1:50; siendo las provincias del Huaura y Huaral las que tuvieron los mayores niveles de seropositividad $(58.8 \%, 10 / 17)$. No se hallaron diferencias estadísticas significativas en las variables edad y sexo.

Palabras clave: Neospora caninum, perros, neosporosis, IFI, aborto

\section{INTRODUCCIÓN}

La neosporosis es una enfermedad parasitaria, producida por un protozoo que provoca alteraciones neuromusculares en el pe- rro, y abortos y mortalidad en terneros (Miró et al., 1999; Hemphill et al., 1999; Hemández et al., 1999; Ortega-Mora et al., 2001), incluyendo lesiones de encefalomielitis (Miró et al., 1999; Paré et al., 1995; Hernández et al., 1999).

${ }^{1}$ Practica privada

${ }^{2}$ Laboratorio de Microbiología y Parasitología Veterinaria, FMV-UNMSM

${ }^{3}$ Clínica de Animales Mayores, FMV- UNMSM

${ }^{4}$ Laboratorio de Medicina Veterinaria Preventiva, FMV-UNMSM

${ }^{5}$ Laboratório Parasitoses, Escola de Medicina Veterinária, Universidade Federal da Bahía, Brasil 
Los primeros indicios de esta enfermedad se remontan a 1984, donde en Noruega se diagnosticó una encefalopatía mortal en perros asociada a un parásito similar al Toxoplasma gondii, aunque antigénicamente diferente, que fue aislado de muestras de cerebro y músculos. Posteriormente, en 1988, con la ayuda de pruebas serológicas e inmunohistoquímicas, se puso en evidencia la presencia de un nuevo parásito con características diferentes al $T$. gondii y que fue nombrado por Dubey como Neospora caninum. A partir de ello se comprobó la infección natural por este parásito en diversas especies animales como rumiantes, carnívoros y équidos (Miró et al., 1999). Posteriormente, se llegó a confirmar que el perro es el hospedero definitivo de Neospora caninum (McAllister et al., 1998).

La neosporosis es considerada en la actualidad como una de las principales causas de aborto y mortalidad neonatal en el ganado bovino (Miró et al., 1999), además de ocasionar problemas neuromusculares en el perro. En estudios realizados en Brasil, se encontró una prevalencia de $21.6 \%$ en perros de establos (de Souza et al., 2002), mientras que en Argentina se determinó que el $73.3 \%$ de los perros de hatos lecheros eran serológicamente positivos a la infección (Basso et al., 1999). En el Perú, estudios de prevalencia de $N$. caninum en bovinos lecheros del valle de Lima indican valores de $29.6 \%$ (Silva, 2002), no existiendo estudios que hayan demostrado la presencia del parásito en perros de establos. Por tal motivo, el objetivo del presente trabajo fue determinar la frecuencia de Neospora caninum en perros de establos lecheros del valle de Lima.

\section{Materiales y Métodos}

\section{Ubicación del estudio}

El presente trabajo se realizó en establos lecheros de explotación intensiva, ubicados entre las provincias norteñas de Huaura y Huaraz, y la sureña de Cañete, así como los establos de las zonas norte y sur cercanas a Lima, abarcando una extensión de alrededor de $300 \mathrm{~km}$.

\section{Tamaño muestral}

Se trabajó con perros que vivían en el interior de los establos. El cálculo del tamaño muestral fue estimado en base al número de establos lecheros presentes en Lima [157 establos según MINAG (2001)]. Además, se consideró la presencia de 3 ó 4 perros por establo, por lo cual se estimó que la población de estos era alrededor de 500.

Para determinar el porcentaje de animales positivos a $N$. caninum se realizó un muestreo previo en 30 perros, encontrándose el $36.6 \%$ de positivos (prevalencia previa) con un error admisible de $10 \%$, motivo por el cual se determinó un tamaño muestral de 100 animales.

\section{Colección de muestras}

Se tomaron muestras de sangre de 104 perros mayores de 3 meses, que vivían en 23 establos lecheros. Las muestras de sangre se obtuvieron por punción de la vena cefálica y recolectada por medio de un equipo de tubos al vacío. El suero se extrajo el mismo día de la recolección y fue conservado a temperatura de congelación $\left(-20^{\circ} \mathrm{C}\right)$ hasta el día de su procesamiento.

\section{Determinación de anticuerpos}

Los anticuerpos contra Neospora caninum fueron determinados mediante la prueba de inmunofluorescencia indirecta (IFI). La positividad del suero fue considerada al observarse fluorescencia completa del taquizoíto, mientras que en la muestra negativa no se aprecia tal fluorescencia o sólo se hace en forma parcial (apical) o incompleta (Paré et al., 1995).

\section{Análisis de datos}

La información de los perros se agrupó de acuerdo a las edad del animal $(<1,1-7$, 
y $>7$ años. Armstrong y Lund, 1996). Se determinó la frecuencia de Neospora caninum, utilizando la fórmula de Thrusfield (1990) y el intervalo de confianza mediante la fórmula de Armitage y Berry (1987). Se utilizó la prueba de Regresión Logística para cuantificar la asociación entre la presencia de la infección en relación con las variables analizadas.

\section{Resultados}

La frecuencia de caninos seropositivos a $N$. caninum en los establos lecheros ubicados a lo largo de la costa del departamento de Lima fue de 32.7 $\pm 9.0 \%$ (34/104) (Cuadro 1).

Los perros procedentes de Huaura y Huaral presentaron una seropositividad superior (58\%) a la observada en las otras zonas geográficas y si bien no fue estadísticamente significativa ( $p>0.05)$, el análisis de riesgo a través de la prueba de regresión lo- gística indicó que dichas zonas representaban un mayor riesgo de infección que las otras bajo estudio. Por otro lado, no se hallaron diferencias estadísticas entre grupos etáreos ni entre sexos ( $p>0.05)$, por lo que el riesgo de infección fue el mismo para todos los estratos.

\section{Discusión}

La frecuencia de $N$. caninum en perros de establos lecheros del valle de Lima $(32.7 \pm 9.0 \%)$ fue muy inferior a la prevalencia hallada por Basso et al. (1999) en Argentina $(73 \%)$, quiénes consideraron que la alta prevalencia podía deberse a las mayores posibilidades de infección por $N$. caninum que tenían esos animales. Sin embargo, si se considera la estrecha relación que existe entre los bovinos y los perros criados en los establos, y la tasa de prevalencia referida por Silva (2002) para bovinos del valle de Lima, se podría concluir que este vínculo existe.

Cuadro 1. Frecuencia de positividad a $N$. caninum en perros que viven en establos lecheros. 2002

\begin{tabular}{lccc}
\hline \multirow{2}{*}{ Lugar } & \multicolumn{2}{c}{ Animales (n) } & \multirow{2}{*}{$\begin{array}{c}\text { Frecuencia } \\
\%\end{array}$} \\
\cline { 2 - 3 } & Muestreados & Positivos & \\
\hline Zona & & & 58.8 \\
$\quad$ Huaura - Huaral & 32 & 10 & 25.0 \\
$\quad$ Lima Norte & 33 & 8 & 27.3 \\
Lima Sur & 22 & 9 & 31.8 \\
Cañete & & 7 & \\
Edad & 16 & & 25.0 \\
$\quad$ 1 año & 78 & 4 & 32.1 \\
1-7 años & 10 & 25 & 50.0 \\
$>$ 7años & & 5 & \\
Sexo & 58 & & 36.2 \\
Macho & 46 & 21 & 28.3 \\
Hembra & 104 & 13 & $32.7 \pm 9.0$ \\
\hline
\end{tabular}


Silva (2002) halló una mayor seroprevalencia de $N$. caninum en bovinos de establos del norte de Lima en relación a establos del sur $(40.8 \pm 9 \%$ vs $22.3 \pm 6.0 \%$, respectivamente), en tanto que en este trabajo se encontró una clara tendencia de mayor cantidad de perros seropositivos en la zona de Huaura y Huaral, lo que podría llevar a considerar las condiciones ecológicas del parásito, así como los factores de manejo y de interacción entre la población de perros y bovinos existente en los hatos en cuestión.

Se tiene evidencia que temperaturas ambientales elevadas servirían como factor predisponente para la infección (Cheadle et al., 1999; Wouda et al., 1999); aunque esto no se pudo verificar en el presente estudio ya que las zonas bajo evaluación no tuvieron mayores diferencias climáticas. Es así que habría que considerar aspectos de manejo intrínsecos para el control de la enfermedad, tales como la eliminación de placentas y fetos muertos, la limitación del acceso de los canes al alimento del ganado, el control de roedores, así como el grado de independencia del establo respecto a sus alrededores; vale decir, el tránsito de animales que pudieran ser portadores de la enfermedad.

La edad no fue un factor de riesgo de importancia en el estudio. Al parecer, la infección tiene que ser perpetuada por transmisión vertical, tanto en bovinos (PereiraBueno et al., 1999b) y en cánidos (Schares et al., 2001); sin embargo, cabe resaltar que en el presente estudio no existió una dispersión homogénea en cuanto a edad de los perros, puesto que la población canina en los establos era mayormente adulta.

Se encontró perros negativos dentro de un establo positivo, y la explicación fue que esos perros no estuvieron en contacto con los animales del hato, de manera que el acceso a fetos o placenta infectadas o animales muertos fueron mínimos; sin embargo, un aspecto que es importante mencionar fue encontrar en otros predios, perros negativos a $N$. caninum pero que andaban libremente por todos los corrales y con acceso a algún posible material infectado. Lamentablemente, no se pudo determinar el grado de neosporosis bovina en estos hatos, factor limitante para el presente estudio, ya que esto solo podría ser explicado por el hecho que el hato sea negativo a $N$. caninum.

La mayoría de los establos muestreados no han introducido bovinos desde hace más de 30 años, de allí que no se podría pensar que la neosporosis entró en estos hatos cerrados a través de las vacas, sino que lo más probable es que el ingreso del parásito haya sido a través del hospedero definitivo. En el país, la importación de perros no tiene exigencias sanitarias muy rigurosas, pudiendo haber entrado a nuestro territorio en los últimos años como portadores del $N$. caninum, los mismos que al ser llevados a los predios ganaderos, introdujeron el parásito al sistema productivo.

Por otro lado, existe la posibilidad que hospederos reservorios pudieran haber introducido el parásito, ya que ensayos realizados por McGuire et al. (1999) en palomas (Columbia livia), inoculados con taquizoítos de $N$. caninum dieron positivo en cultivos celulares, PCR, serología e histología, abriendo la posibilidad a que los perros oriundos hayan sido infectados luego de ingerir estos hospederos ocasionales infectados. Asimismo, también existe la posibilidad que la enfermedad haya ingresado al país a través de la importación de alimento contaminado con ooquistes del protozoario (Miró et al., 1999). La frecuencia de la infección por $N$. caninum en perros de los establos lecheros parece estar ligada a la prevalencia en bovinos, en base a los estudios realizados por Silva (2002) así como los hallados en el presente trabajo.

Se recomienda evitar que los perros tomen contacto directo con el ganado y con su fuente de alimentos, para impedir la transmisión horizontal; así como eliminar fetos abortados, placentas y animales muertos, que pudieran infectar al hospedero definitivo. 


\section{Conclusiones}

- Existen perros infectados con Neospora caninum en establos lecheros del valle de Lima.

- La frecuencia de infección en caninos fue ligeramente mayor en las provincias de Huaura y Huaral, sugiriendo que existe un mayor riesgo de infección respecto a las otras áreas en consideración.

- La edad y el sexo en los perros no constituyó un factor influyente en la frecuencia del parásito, lo que implicaría una transmisión vertical del agente a la descendencia.

\section{Literatura Citada}

1. Armitage, P.; G. Berry. 1987. Statistical methods in medical research. $2^{\text {nd }}$ ed.p $115-$ 120. Blackwell Scientific Publications. Great Britain.

2. Basso, W.; L. Venturini; M. Rambeaud; J.M. Uazaga; D. Bacigalupe. 1999. Prevalencia de infección por Neospora caninum en perros de ciudad y de tambo. En: XIV Congreso Latinoamericano de Parasitología. Acapulco, México. p 90.

3. Cheadle, M.A.; D.S. Lindsay; B.L. Blagburn. 1999. Prevalence of antibodies to Neospora caninum in dogs. Vet. Parasitol. 85: 325-330.

4. De Souza, S.; J. Guimaraes; F. Ferreira; J. Dubey; S. Gennari. 2002. Prevalence of Neospora caninum antibodies in dogs from dairy cattle farms in Parana, Brazil. J. Parasitol. 88: 408-409.

5. Hemphill, A.; N. Fuchs; S. Sonda; A. Hehl. 1999. The antigenic composition of Neospora caninum. Int. J. Parasitol. 29: 1175-1188.

6. Hernández, R.S.; M.A.J. Martínez; P.P.N. Gutierrez. 1999. Neosporosis. En: Parasitología Veterinaria. Cordero del Campillo, M.; F.A. Rojo. p 330-333. Ed. Interamericana. Madrid, España.

7. McAllister, M.M.; J.P. Dubey; D.S. Lindsay; W. Jolley; R.A. Wills; A.M. McGuire. 1998. Dogs are definitive hosts of Neospora caninum. Inter. J. Parasitol. 28: 1473-1478.

8. McGuire, A.M.; M. McAllister; R.A. Wills; J.D. Tranas. 1999. Experimental inoculation of domestic pigeons (Columbia livia) and zebra finches (Poephila guttata) with Neospora caninum tachyzoites. Int. J. Parasitol. 29:1525-1529.

9. MINAG . 2001. Censo Nacional de Unidades Especializadas de Producción Pecuaria Intensiva (UEPPI) 2000. OIA MINAG. Lima, Perú. p 143.

10. Miró, G.; A. Alonso; C. Frisuelos; L. Martín. 1999. Etiología y biología. En: Patología de la reproducción de etiología parasitaria (II): Neosporosis. Rev. Aula Veterinaria Bovis 88: 11-17.

11. Ortega-Mora, L.M.; E. Collantes; G. Alvarez. 2001. La neosporosis del ganado bovino: Una enfermedad emergente. MV Rev. Cien. Vet. 17: 7-14.

12. Paré, J.; S. Hietala; M. Thurmond. 1995. Interpretation of an indirect fluorescent antibody test for diagnosis of Neospora sp. infection in cattle. J. Vet. Diagn. Invest. 7: 273-275.

13. Pereira-Bueno, J.; A. QuintanillaGozalo; L. Del Río-González; L.M. Ortega-Mora. 1999. Epidemiología (II): Transmisión y factores de riesgo. En: Patología de la reproducción de etiología parasitaria (II): Neosporosis. Rev. Aula Veterinaria Bovis 88: 35-42.

14. Schares, G.; U. Wenzel; T. Müller; F.J. Conraths. 2001. Serological evidence for naturally occurring transmission of Neospora caninum among foxes (Vulpes vulpes). Int. J. Parasitol. 31: 418-423.

15. Silva, S. 2002. Seroprevalencia de Neospora caninum en ganado bovino lechero de la cuenca de Lima. Tesis Médico Veterinario. Facultad de Medicina Veterinaria, Univ. Nacional Mayor de San Marcos, Lima. 44 p.

16. Thrusfield, M. 1990. Epidemiología Veterinaria. p 228-230. Ed. Acribia. España.

17. Wouda, W.; C.J.M. Bartels; A.R. Moen. 1999. Characteristics of Neospora caninum-associated abortion storms in dairy herds in The Netherlands (1995 1997). Theriogenology 52: 233-245. 